\title{
Children's response speed as a function of delay of reward at different distances from the goal and incentive value
}

\author{
ANEES A. SHEIKH', DEPARTMENT OF PSYCHOLOGY, \\ MARQUETTE UNIVERSITY, Milwaukee, Wisc. 53233
}

Fifty-six kindergarten children were each administered 19 immediately-rewarded trials followed by nine trials with delayed reward on a lever-pulling apparatus. The Ss formed four groups according to incentive value and distance of delay from the goal. The starting speed of children decreased after the introduction of delay. The inhibiting effect of delay was significant only near the goal. The incentive variable did not enter into any significant relationship.

Both theoretical speculation (Amsel, 1958; Spence, 1956) and empirical evidence (Endsley, 1966; Holton, 1961) suggest that a thwarting event (e.g., restraint, nonreward) near a goal has different effects on behavior than when it occurs away from the goal. For example, Holton showed that a group of children introduced to nonreward close to the goal showed a significantly greater increase in amplitude of response than a group experiencing nonreward at a point farther removed from the goal. This study attempted to determine whether similar relationships would hold when delay of reward is introduced at different distances from the goal with response speed as the dependent variable. In addition, incentive value was included as an independent variable.

Method. The Ss were 56 kindergarten children obtained from a public school in London, Ontario. The lever-pulling, marble-dispensing apparatus used was as described by Ryan \& Cantor (1962). The Ss were divided into four subgroups: high incentive with delay near the goal $(\mathrm{NH})$, high incentive with delay far from the goal (FH), low incentive with delay near the goal (NL), and low incentive with delay far from the goal (FL).

Children in the high incentive group were shown a collection of about 20 toys spread on the table and were asked to choose any two toys which they would prefer to win in the "game" to be played. The Ss in the low incentive group were merely informed that they could win a balloon and had no opportunity to state a preference.

The manipulation of the distance from the goal variable was in relation to the location of a piece of removable black tape which indicated to $S$ how many marbles he had to acquire before he could trade them for the toys. The number of reinforcements prior to the introduction of delay of reward was kept constant for all the Ss. Each $S$ was given two immediately-rewarded practice trials. Then 19 immediately-rewarded trials were followed by nine trials with delayed reward. The intertrial interval was just long enough to enable $\mathrm{E}$ to record the times and reset the timers (i.e., 8 to $10 \mathrm{sec}$ ).

Results. All data for response time were converted to speeds $(1 / \mathrm{t} \mathrm{sec})$. For each $\mathrm{S}$ mean movement and starting speeds were obtained for the eight trials preceding delay (I scores) and for the first eight delay trials (D scores).

Starting Speeds. To evaluate the changes in speed following the introduction of delay, a Lindquist Type III (Lindquist, 1953) analysis of variance was performed on I and D scores. For within Ss, significant effects were obtained for immediate (I) vs delayed (D) reinforcement conditions ( $F=49.60, \mathrm{df}=1, \mathrm{p}<.001$ ) and for the interaction between the reinforcement condition and distance from the goal $(\mathrm{F}=5.80, \mathrm{df}=1, \mathrm{p}<.025)$.

Two $t$ tests based on related scores compared I vs D scores for Group $\mathrm{N}(\mathrm{NH}+\mathrm{NL})$ and also for Group $\mathrm{F}(\mathrm{FH}+\mathrm{FL})$. The $t$ values of $7.18(\mathrm{df}=27, \mathrm{p}<.001)$ and $1.75(\mathrm{NS})$, respectively, indicated a significant decrease in the starting speed, following delay, only for Group N.

Out of the total of $56 \mathrm{Ss}, 45$ slowed down following delay ( $\mathrm{p}<$ $.001)$. All of the $14 \mathrm{Ss}$ in Group NH $(\mathrm{p}<.001), 11$ in Group FH
( $p<.05)$, and 12 in Group NL $(p<.005)$, but only eight in Group FL (NS) exhibited a decrement in starting speed.

Movement Speeds. The movement speed data were analyzed in the same manner as starting speed but none of the results were significant.

Discussion. The finding of decrement in starting speeds, with a shift from immediate to delayed reward, is consistent with Rieber's (1961) results and with Amsel's (1958) frustration theory that attributes aversive motivational properties to frustration. Frustration is regarded as providing stimulus cues that elicit avoidance behavior. It is suggested here that the sudden introduction of delay following 19 immediately-rewarded trials elicited frustration-produced competing responses which interfered with the starting response. This finding is also explainable in terms of Spence's (1956) delay hypothesis; that is, delay of reward facilitates the association of extraneous responses which are incompatible with the instrumental response itself.

A significant interaction between reinforcement condition and distance from the goal indicated a greater decrement in starting speed when delay was introduced near the goal. Since anticipation of reward $(\mathrm{rg})$ is assumed to be stronger near the goal (Amsel, 1958), delay near the goal is assumed to be more frustrating and leads to a higher drive level. If the competing responses are prominent, this heightened drive level would presumably multiply their habit strength and thus increase the probability of their occurrence during the delay period. These competing responses could also get reinforced when the marble reward is finally delivered, and would become conditioned to the apparatus. This interpretation, however, is not unequivocal. If one assumes that nearer the goal, the greater the $\mathrm{rg}_{\mathrm{g}}$, one might also expect faster starting speeds for the group frustrated near the goal as opposed to the group frustrated far from the goal, in the pre-delay period. But this was not the case. Perhaps the high interest in the game per se led to such a high speed of responding that some of the $S s$ reached their physiological limit, and the addition of any extra $\mathrm{rg}_{\mathrm{g}}$ could not manifest itself.

The incentive variable did not enter into any significant relationship either for starting or for movement speed. Probably, the high interest in the game itself rendered any additional incentive motivation ineffective. It could also be possible that the children's interest was not mainly centered in the toy. They might have been more interested in the token rewards (marbles). It may be mentioned that it was assumed that a balloon is a low incentive object, but there was nothing in the situation to compare it with, thereby assigning it a relatively low status. It is possible that a balloon was acting as a rather high incentive.

\section{REFERENCES}

AMSEL, A. The role of frustrative nonreward in a noncontinuous reward situation. Psychol Bull., 1958, 55, 102-119.

ENDSLEY, R. C. Effortfulness and blocking at different distances from the goal as determinant of response speed and amplitude. $J$. exp. child Psychol., 1966, 3, 18-30.

HOLTON, R. B. Amplitude of an instrumental response following the cessation of reward. Child Develpm, 1962, 32, 107-116.

LINDQUIST, E. F. Design and analysis of experiments in psychology and education. Boston: Houghton Mifflin Co., 1953.

RIEBER, M. Shifts in response reward interval and its effect upon response speed. Psychol. Rep., 1961, 9, 393-398.

RYAN, T. J., \& CANTOR, C. N. Response speed in children as a function of reinforcement schedule. Child Develpm, 1962, 33, 871-878.

SPENCE, K. W. Behavior theory and conditioning. New Haven: Yale University Press, 1956.

\section{NOTE}

1. The writer wishes to express his sincere appreciation to Thomas Ryan for his advice and assistance. Thanks are also due to the Board of Education, London, Ontario, for permission to use the Ss in this study. 